\title{
ÍNDICE DE QUALIDADE DA ÁGUA EM TRECHOS DO RIO TURVO SUJO, VIÇOSA - MG
}

\author{
Daniele Gonçalves Nunes ${ }^{1}$, Demetrius David da Silva², Antonio Teixeira de Matos $^{3}$
}

\section{RESUMO}

Neste trabalho, objetivou-se caracterizar, da nascente à foz, a qualidade das águas do Rio Turvo Sujo em seis trechos. O trabalho foi desenvolvido em quatro campanhas ao longo dos períodos seco e chuvoso, durante os meses de agosto e novembro de 2006 e fevereiro e junho de 2007. Nas campanhas referentes ao período seco, realizadas nos meses de agosto de 2006 e junho de 2007, obtiveram-se, para cada trecho, os Índices de Qualidade da Água (IQA) que variaram de muito ruim a médio em agosto de 2006, sendo o trecho de pior qualidade, o trecho II (a montante do encontro com o córrego do Grama), e de ruim a médio, em junho de 2007. Para as campanhas referentes ao período chuvoso, realizadas nos meses de novembro de 2006 e fevereiro de 2007, os IQA obtidos variaram de muito ruim a excelente em fevereiro de 2007, e médio para todos os trechos em novembro de 2006. As variáveis que mais interferiram negativamente no IQA foram coliformes termotolerantes (CF), demanda bioquímica de oxigênio (DBO), turbidez e oxigênio dissolvido (OD), caracterizando o lançamento de efluentes de alta carga orgânica.

Palavras-chave: IQA, qualidade da água, Rio Turvo Sujo

\section{ABSTRACT \\ WATER QUALITY INDEX IN SOME 'TURVO SUJO’ RIVER TRACKS, VIÇOSA - MG}

This study was done to assess the water quality of 'Turvo Sujo' river along six tracks, starting from the river's origin till its mouth. There were four campaigns during the dry and rainy seasons. In the dry period campaigns conducted in August 2006 and June 2007, the water quality index (WQI) of each track varied between very bad to average in August 2006, with track II being the worst quality (upstream encounters with Grama stream), and bad to average in June 2007. In the rainy season campaigns carried out in November 2006 and February 2007, the WQI varied between very bad to excellent in February 2007, and average in all tracks in November 2006. The variables that most depreciated WQI were thermotolerant coliforms, biochemical oxygen demand, turbidity and dissolved oxygen, suggesting discharge of effluents with high organic matter.

Keywords: WQI, water quality, Turvo Sujo river

\section{Recebido para publicação em 11/06/2008. Aprovado em 14/07/2010.}

1- Engenheira Ambiental, Mestre em Engenharia Agrícola/UFV, Volta Redonda-RJ, E-mail: daniele_gnunes@hotmail.com

2- Engenheiro Agrônomo, Professor do Departamento de Engenharia Agrícola/UFV, Viçosa-MG, E-mail: demetrius@ufv.br

3- Engenheiro Agrícola, Professor do Departamento de Engenharia Agrícola/UFV, Viçosa-MG, E-mail: atmatos@ufv.br 


\section{INTRODUÇÃO}

A qualidade da água é resultante de fenômenos naturais e de ações antrópicas, podendo-se dizer que é função do uso e ocupação do solo na bacia hidrográfica. A interferência do homem é uma das maiores causas de alteração da qualidade da água, seja através de uma forma concentrada, com a geração de efluentes domésticos ou industriais, ou de uma forma dispersa, com aplicação de defensivos e insumos agrícolas, contribuindo para a incorporação de substâncias químicas nos cursos d'água, alterando sua qualidade. Desse modo, a utilização e ocupação do solo têm uma implicação direta na qualidade da água.

A qualidade da água pode ser avaliada por meio dos índices de qualidade que refletem o nível de salubridade da água, sendo baseados em algumas variáveis predeterminadas. Em alguns casos, estes índices refletem o comportamento do ecossistema e, em outros, indicam a condição do ambiente aquático. O objetivo principal destes índices é determinar o potencial de disfunções do ecossistema e permitir melhor compreensão das fontes de contaminação e das decisões de manejo mais eficazes (ONGLEY, 2000).

Os índices da qualidade de água têm diversas finalidades como distribuição de recursos e determinação de prioridades; comparação de condições ambientais em diferentes áreas geográficas; determinação do cumprimento da legislação ambiental; análise de tendências, avaliação de mudanças na qualidade ambiental, em determinado período de tempo e acompanhamento da qualidade dos recursos hídricos superficiais; informação ao público; pesquisa científica; e identificação de problemas de qualidade da água que demandem estudos especiais em trechos de rios.

A Cetesb (Companhia de Tecnologia Ambiental do Estado de São Paulo) utilizou de 1975 a 2001, o Índice de Qualidade das Águas (IQA) para servir de informação básica de qualidade da água para o público em geral, bem como para o gerenciamento ambiental das 22 UGRHIs - Unidades de Gerenciamento dos Recursos Hídricos em que se divide o Estado de São Paulo. A partir de 2002, a Cetesb passou a utilizar índices específicos para os principais usos do recurso hídrico (CETESB, 2007).

Para águas destinadas ao abastecimento público, a Cetesb utiliza o IAP (que é o produto da ponderação dos resultados atuais do IQA (Índice de Qualidade de Águas) e do Isto (Índice de Substâncias Tóxicas e Organolépticas), que é composto pelo grupo de substâncias que afetam a qualidade organoléptica da água, bem como de substâncias tóxicas). No caso de águas destinadas à proteção da vida aquática, utilizase o IVA (tem o objetivo de avaliar a qualidade das águas para fins de proteção da fauna e flora em geral) e, por fim, para águas destinadas ao banho, utiliza-se a classificação da praia.

No estudo em questão, foi utilizado o Índice de Qualidade da Água, IQA, proposto pelo Igam (Instituto Mineiro de Gestão das Águas). Este índice difere do IQA, utilizado pela Cetesb, por considerar nitrato em vez de nitrogênio total.

O IQA, por reunir em um único resultado os valores de nove diferentes parâmetros, oferece ao mesmo tempo vantagens e limitações. A vantagem reside no fato de sumarizar a interpretação de nove variáveis em um único número, facilitando a compreensão da situação para o público leigo. A limitação relaciona-se à perda na interpretação das variáveis individuais e da sua relação com as demais. Soma-se a isto o fato de este índice ter sido desenvolvido de forma a possibilitar a avaliação do impacto dos esgotos domésticos nas águas utilizadas para abastecimento público, não representando efeitos originários de outras fontes poluentes (IGAM, 2006). Entretanto, este estudo é de grande importância, pois o Rio Turvo Sujo, apesar de pertencer à bacia do Rio Doce, não consta no banco de dados do Projeto Águas de Minas, que é o responsável pelo monitoramento da qualidade das águas superficiais e subterrâneas de Minas Gerais. Em execução desde 1997, o programa disponibiliza uma série histórica da qualidade das águas no Estado e gera dados indispensáveis ao gerenciamento correto dos recursos hídricos (IGAM, 2006). Desse modo, este trabalho vem complementar e preencher a ausência de alguns destes dados.

A bacia, objeto de estudo no presente trabalho, 
é a do Rio Turvo Sujo, situada na bacia do Rio Doce, abrangendo os municípios de Viçosa, Coimbra, Cajuri e Teixeiras. Pode ser considerada uma bacia importante para a região em termos de abastecimento de água para a população, diluição de efluentes domésticos e industriais, pecuária e agricultura. Em alguns trechos do Rio ainda se pode notar a conservação das margens e do leito, sem expressivas alterações antrópicas. O trecho onde ocorrem maiores intervenções está no município de Viçosa, no qual há o encontro do Rio Turvo Sujo com o Rio São Bartolomeu, um de seus afluentes mais importantes. Este último corta a cidade de Viçosa e recebe grande quantidade de despejos ricos em carga orgânica, provocando um decaimento da qualidade da água do Rio Turvo Sujo após a confluência com o ribeirão São Bartolomeu.

Em função do exposto, os objetivos do presente trabalho são obter o Índice de Qualidade da Água (IQA) em dez pontos do Rio Turvo Sujo para duas épocas distintas (período seco e chuvoso) e identificar quais variáveis são mais significativas no cálculo do IQA.

\section{MATERIAL E MÉTODOS}

\section{Caracterização da área em estudo}

A área do presente estudo abrange a bacia hidrográfica do Rio Turvo Sujo, com uma área de drenagem de 406,44 $\mathrm{km}^{2}$, abrangendo as cidades de Coimbra, Cajuri, Viçosa, Teixeiras e Guaraciaba, em Minas Gerais, situa-se entre as coordenadas geográficas $42^{\circ} 42^{\prime}$ e $42^{\circ} 58^{\prime}$ de longitude oeste e $20^{\circ} 39^{\prime}$ e $20^{\circ} 53^{\prime}$ de latitude sul. O Rio Turvo Sujo, afluente da margem direita do Rio Turvo Limpo, tem, aproximadamente, $71 \mathrm{~km}$ de comprimento e nasce na cidade de Coimbra. Seu principal afluente é o Ribeirão São Bartolomeu, que passa pela cidade de Viçosa e acaba por receber grande quantidade de efluentes. Apresenta altitude média de 775 metros, com cotas extremas de 600 e 945 metros.

A microbacia do Ribeirão São Bartolomeu integra a bacia do Rio Turvo Sujo e encontrase totalmente inserida no município de Viçosa, localizado na mesorregião da Zona da Mata Mineira, a uma latitude $20^{\circ} 45^{\prime} 14^{\prime \prime}$ sul e a uma

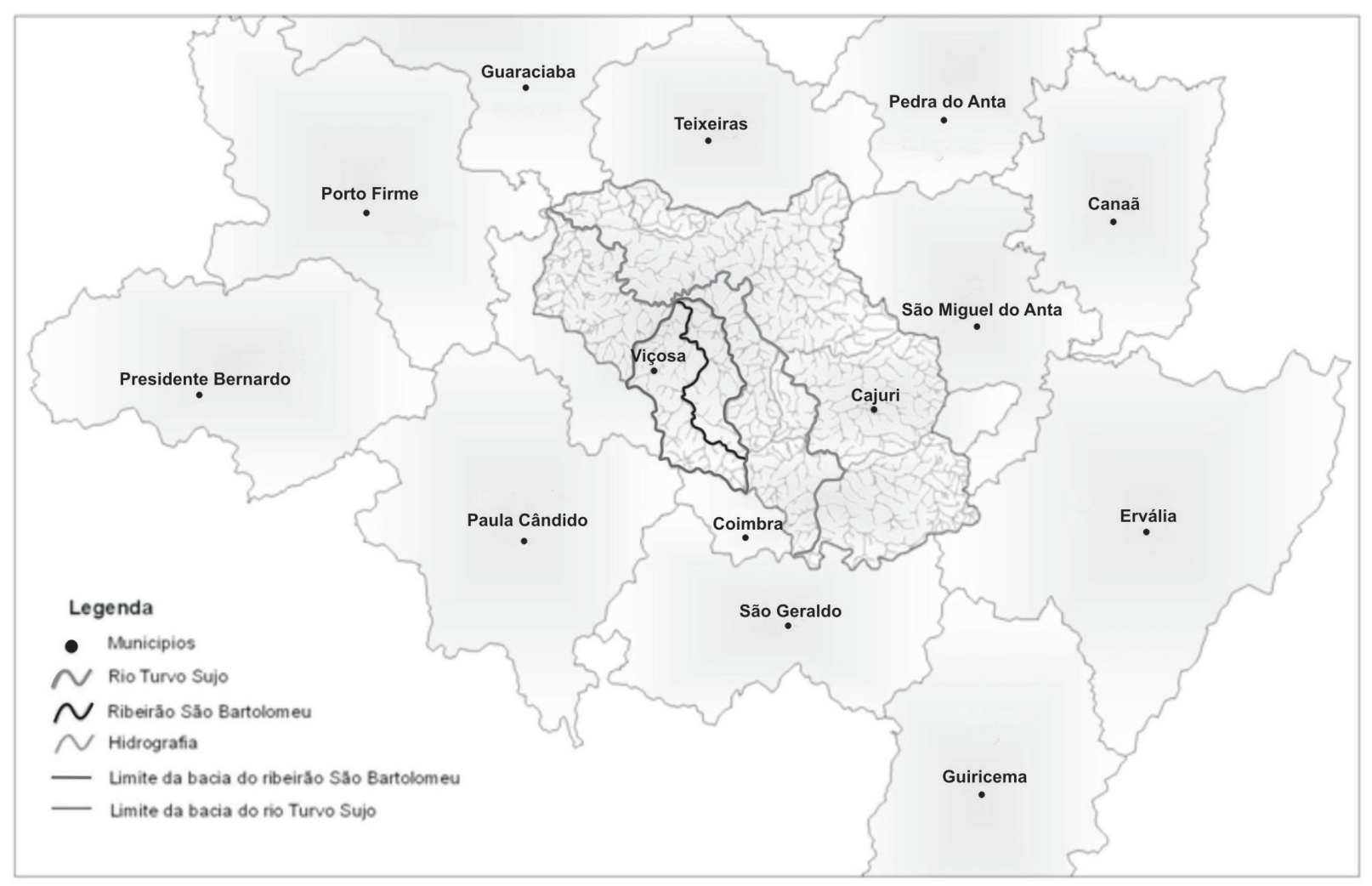

Figura 1. Localização da bacia do rio Turvo Sujo. 
longitude $42^{\circ} 52^{\prime} 55^{\prime \prime}$ oeste (COMBASB, 1994). O Ribeirão São Bartolomeu deságua no Rio Turvo Sujo, na localidade conhecida como Barrinha. O Rio Turvo Sujo, por sua vez, encontra-se com o Rio Turvo Limpo na localidade conhecida como Duas Barras (RIBEIRO, 2002). A cidade de Viçosa abrange grande parte da bacia do Rio Turvo Sujo e tem uma população de 70.404 habitantes, segundo o censo do ano de 2007, realizado pelo Instituto Brasileiro de Geografia e Estatística (IBGE, 2008).

\section{Amostragem para fins de determinação do IQA e autodepuração}

Foram dez pontos de coleta ao longo do Rio Turvo Sujo e as amostras foram coletadas em recipientes plásticos com volume de dois litros para análises de $\mathrm{pH}, \mathrm{DBO}$, nitrato, fosfato, turbidez e sólidos. Em recipientes plásticos de $500 \mathrm{~mL}$, foram coletadas amostras de água para análises de coliformes totais e termotolerantes devido à necessidade de frascos esterilizados. Por último, em vidros especiais com capacidade de $300 \mathrm{~mL}$, com rolha esmerilhada (frascos de
DBO), foram coletadas amostras de água para análises de oxigênio dissolvido. As medições de temperatura também foram feitas "in loco" utilizando termômetro eletrônico.

Os pontos de amostragem foram escolhidos de acordo com o posicionamento dos tributários mais importantes. Adotou-se o procedimento de amostragens no Rio Turvo Sujo a montante da confluência com o tributário em questão e ainda na foz do tributário. Os pontos selecionados estão apresentados na Figura 2 e identificados no Quadro 1.

No momento da amostragem, o frasco foi mergulhado e enxaguado, de duas a três vezes, nas águas em que foram realizadas as coletas. $\mathrm{O}$ frasco foi mergulhado de boca para baixo e virado lentamente no sentido contra a corrente até que fosse completamente preenchido com o líquido.

As amostragens ocorreram em dois períodos, seco e chuvoso, com quatro campanhas para qualidade de água, como apresentado no Quadro 2.

A distribuição temporal foi baseada no regime pluviométrico que influencia diretamente o nível hidrológico. As médias físico-químicas são consideradas instantâneas de uma dada condição ambiental.

Quadro 1. Identificação dos pontos de amostragem

\begin{tabular}{clccc}
\hline ID & \multicolumn{1}{c}{ Pontos } & Altitude $(\mathrm{m})$ & Latitude $\left({ }^{\circ} \underline{\mathrm{S}}\right)$ & Longitude $\left({ }^{\circ} \mathrm{W}\right)$ \\
\hline 1 & Nascente Turvo Sujo (Coimbra) & 731 & $-20,8683$ & $-42,8036$ \\
2 & Montante do Encontro Córrego Grama & 711 & $-20,8462$ & $-42,8007$ \\
3 & Córrego do Grama & 719 & $-20,846$ & $-42,8007$ \\
4 & Montante Encontro Cristal & 651 & $-20,7497$ & $-42,8373$ \\
5 & Rio Cristal & 656 & $-20,7515$ & $-42,8372$ \\
6 & Montante Encontro Sta Tereza & 643 & $-20,7171$ & $-42,8469$ \\
7 & Ribeirão Santa Tereza & 645 & $-20,7166$ & $-42,8464$ \\
8 & Montante Encontro Ribeirão São Bartolomeu & 616 & $-20,7313$ & $-42,8912$ \\
9 & Ribeirão São Bartolomeu & 618 & $-20,7319$ & $-42,8906$ \\
10 & Foz do Rio Turvo Sujo & 596 & $-20,679$ & $-42,9672$ \\
\hline
\end{tabular}

Quadro 2. Datas das campanhas

\begin{tabular}{|c|c|c|}
\hline Tipo de campanha & Época & Datas \\
\hline \multirow{3}{*}{ Qualidade da água } & Seca & $15 / 08 / 2006$ \\
\hline & & $05 / 06 / 2007$ \\
\hline & Chuvosa & $07 / 11 / 2006$ \\
\hline
\end{tabular}




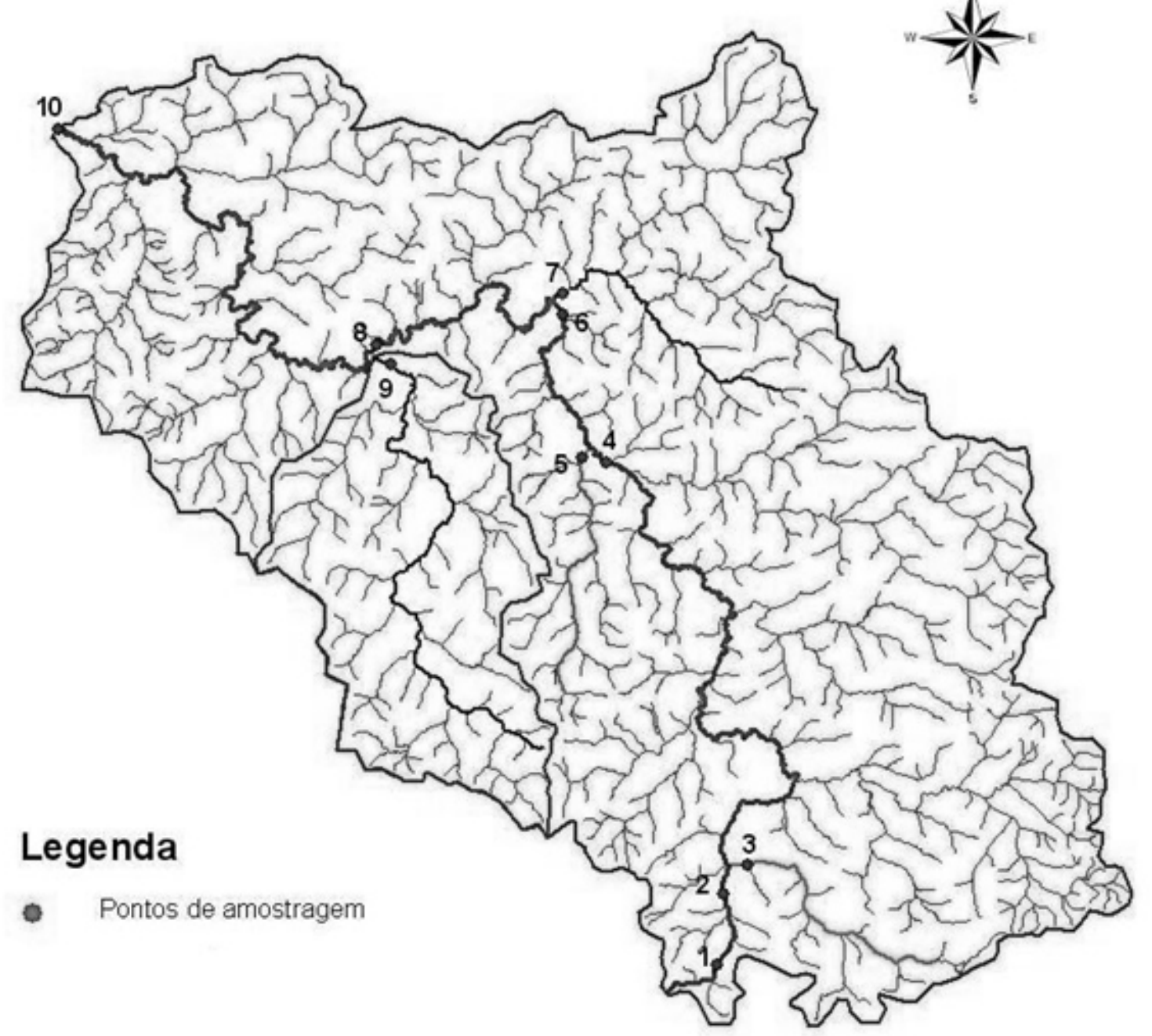

Figura 2. Localização dos pontos selecionados de coleta na bacia do rio Turvo.

Foram utilizadas caixas de isopor com gelo para o acondicionamento das amostras até que fossem conduzidas ao Laboratório de Qualidade da Água, do Departamento de Engenharia Agrícola - UFV, onde foram refrigeradas a $4{ }^{\circ} \mathrm{C}$ e realizadas as análises em triplicata no prazo não superior a 24 horas. Foram realizadas análises dos seguintes parâmetros: Potencial Hidrogeniônico $(\mathrm{pH})$, Coliformes Termotolerantes, Nitrogênio total, Fósforo total, Turbidez, Sólidos Totais, Demanda Bioquímica de Oxigênio (DBO) e Oxigênio Dissolvido (OD).

\section{Determinação dos parâmetros de qualidade da água}

Para análise do $\mathrm{pH}$, foi utilizado o método eletrométrico; a contagem de coliformes termotolerantes foi feita pelo método enzimático de autoanálise Colilert; o nitrogênio total foi quantificado utilizando o método Kjeldahl total; o fósforo total com o método fósforo - molíbdico; a medição da turbidez foi feita utilizando um turbidímetro; os sólidos totais foram quantificados pelo método da estufa, sob temperatura de $103{ }^{\circ} \mathrm{C}$ a $105{ }^{\circ} \mathrm{C}$; e, por último, a determinação da DBO foi feita utilizando o método Winkler (iodométrico). A metodologia utilizada para as análises foi baseada no Standard Methods for the Examination of Water and Wastewater (APHA, 1998) e no caderno didático de práticas de Qualidade do solo e da água (ENG 647) do Departamento de Engenharia Agrícola (MATOS, 2004). 


\section{IQA - Índice de Qualidade da Água}

Para a obtenção do IQA, foram consideradas as variáveis oxigênio dissolvido, coliformes termotolerantes, $\mathrm{pH}$, demanda bioquímica de oxigênio, nitrato, fosfato, temperatura da água e sólidos totais. O IQA foi obtido pelo produtório ponderado das qualidades de água correspondentes às variáveis:

$$
\begin{aligned}
& I Q A=\prod_{i=1}^{n} q_{1}^{0,17} \times q_{2}^{0,15} \times q_{3}^{0,12} \times q_{4}^{0,10} \times q_{5}^{0,10} \times q_{6}^{0,10} \times \\
& q_{7}^{0,10} \times q_{8}^{0,08} \times q_{9}^{0,08}
\end{aligned}
$$

em que

IQA - índice de qualidade da água, um número de 0 a 100 ;

$\mathrm{q}_{\mathrm{i}}$ - qualidade do i-ésimo parâmetro, um número entre 0 a 100 ; e

$\mathrm{W}_{\mathrm{i}}$ - peso correspondente ao i-ésimo parâmetro, um número entre 0 e 1.

Os pesos utilizados no cálculo do IQA, estabelecidos pelo IGAM (2004), podem ser observados no Quadro 3.

Os pesos são aplicados exponencialmente, portanto, quando os pesos são aplicados às avaliações de qualidade que estão nos extremos, a contribuição das variáveis ao valor final do índice é muito menor (quando $\mathrm{q}_{\mathrm{i}}$ se aproxima de zero) ou muito maior (quando $\mathrm{q}_{\mathrm{i}}$ se aproxima de 100) que quando aplicado a valores médios de $\mathrm{q}_{\mathrm{i}}$ (ALMEIDA, 2006).

A partir do valor obtido no cálculo do IQA, foi possível fazer a classificação do nível de qualidade da água em questão, conforme especificado no Quadro 4, proposto por IGAM (2006).

A utilização de uma escala espectral colorida para ilustrar a qualidade de água obtida para determinado trecho do curso de água foi instituída para facilitar a rápida interpretação das condições ambientais de grandes bacias e facilitar o entendimento do público. À condição de maior precariedade na qualidade foi atribuída a cor vermelha, representada pela Escala de Cores CMYK com preto $70 \%$, a cor laranja corresponde à qualidade ruim, representada com preto $55 \%$, a cor amarela corresponde à qualidade média, representada com preto $35 \%$, a cor verde corresponde à qualidade boa, representada com preto $90 \%$ e à melhor qualidade atribui-se a cor azul, representada com preto $100 \%$.

Quadro 3. Pesos correspondentes aos parâmetros do IQA

\begin{tabular}{lcc}
\hline Variável & Peso $\left(\mathrm{w}_{\mathrm{i}}\right)$ & $\mathrm{q}$ \\
\hline Oxigênio dissolvido & 0,17 & $\mathrm{q}_{1}$ \\
Coliformes termotolerantes & 0,15 & $\mathrm{q}_{2}$ \\
pH & 0,12 & $\mathrm{q}_{3}$ \\
DBO & 0,10 & $\mathrm{q}_{4}$ \\
Nitrato & 0,10 & $\mathrm{q}_{5}$ \\
Fosfato & 0,10 & $\mathrm{q}_{6}$ \\
Variações de temperatura & 0,10 & $\mathrm{q}_{7}$ \\
Turbidez & 0,08 & $\mathrm{q}_{8}$ \\
Resíduos totais (sólidos totais) & 0,08 & $\mathrm{q}_{9}$ \\
\hline
\end{tabular}

Quadro 4. Classificação da qualidade da água segundo o IQA

\begin{tabular}{ccc}
\hline Nível de Qualidade & Faixa & Cores \\
\hline Excelente & $90<$ IQA $\leq 100$ & Azul \\
Bom & $70<$ IQA $\leq 90$ & Verde \\
Médio & $50<$ IQA $\leq 70$ & Amarelo \\
Ruim & $25<$ IQA $\leq 50$ & Laranja \\
Muito Ruim & $00<$ IQA $\leq 25$ & Vermelho \\
\hline
\end{tabular}

Fonte: Igam (2006).

\section{REVENG}

459-468 p. ENGENHARIA NA AGRICULTURA, VIÇOSA - MG, V.19 N.5, SETEMBRO / OUTUBRO 2011 


\section{RESULTADOS E DISCUSSÕES}

\section{Caracterização do Rio Turvo Sujo}

$\mathrm{Na}$ Figura 3 estão apresentados os Índices de Qualidade de Água para os trechos do Rio Turvo Sujo, desde a nascente até a foz, baseados nas amostras de água.

Utilizou-se o critério do Igam, no qual se atribuiu ao trecho a montante do ponto de coleta o valor do IQA obtido para o mesmo.

Com base na Figura 3, pode-se classificar a qualidade das águas do Rio Turvo Sujo, em geral, de média a ruim. O pior trecho foi a montante da confluência com o Córrego do Grama até próximo do ponto 1 (nascente) nos meses de agosto de 2006 e fevereiro de 2007, que se situa a jusante da cidade de Coimbra, recebendo grande quantidade de cargas orgânicas, o que provoca uma expressiva queda da qualidade da água neste trecho. Já o melhor trecho foi a nascente (a montante do ponto 1) no mês de fevereiro de 2007, situado a montante da cidade de Coimbra. Isto, provavelmente, pelo maior volume
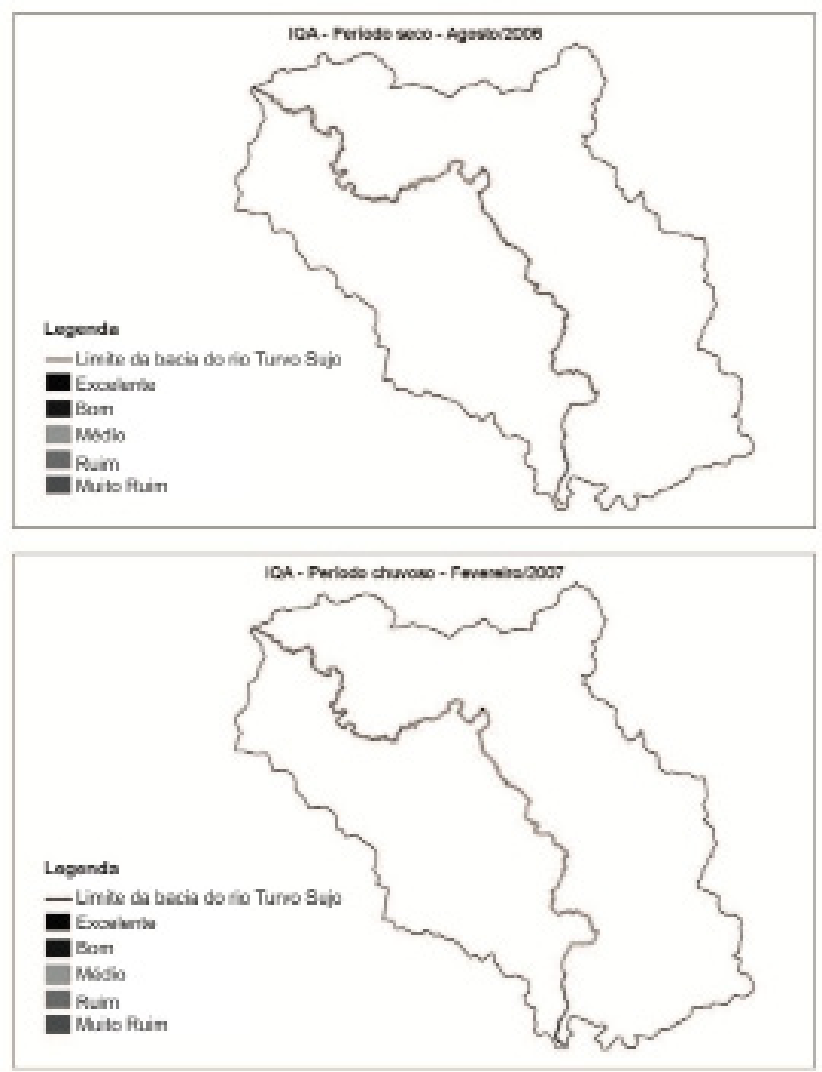

de chuvas e consequente aumento da vazão do curso de água que causou uma diluição dos possíveis poluentes presentes na água.

\section{Variáveis que mais interferiram no IQA}

Baseando-se no Quadro 5, pode-se fazer uma análise de quais variáveis mais influenciaram na diminuição do IQA. Os valores abaixo de 50 foram destacados com a cor cinza.

De acordo com o Quadro 5, pode-se observar que a variável que mais contribuiu para a diminuição do IQA no Rio Turvo Sujo foi a contagem de coliformes termotolerantes $\left(\mathrm{q}_{\mathrm{CF}}\right)$, sendo significativa em todas as campanhas. A presença de elevadas quantidades de coliformes termotolerantes indica a contaminação da água por organismos patogênicos e está diretamente relacionada com o lançamento de dejetos de animais de sangue quente, como, por exemplo, esgotos domésticos. Isto pode ser justificado pelo lançamento de efluentes das cidades do entorno da bacia do Rio Turvo Sujo, principalmente Coimbra e Viçosa.
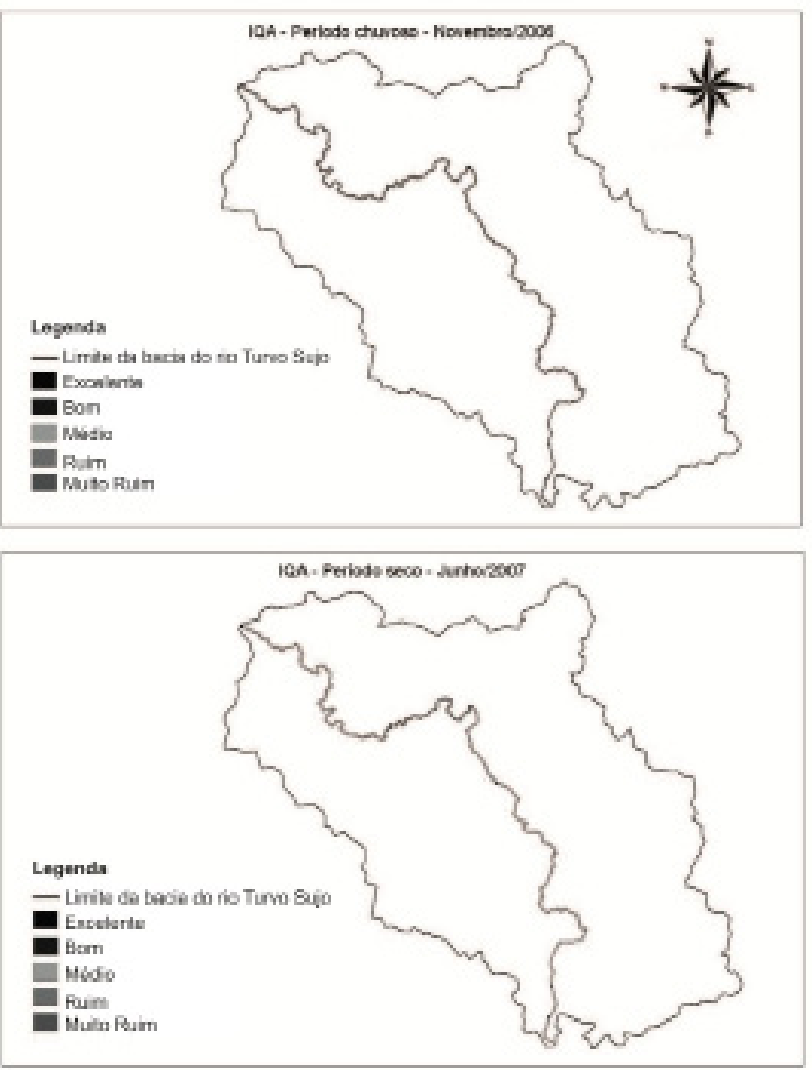

Figura 3. IQA dos trechos do Rio Turvo Sujo nos períodos seco e chuvoso. 
Quadro 5. Campanhas de amostragem de qualidade da água no Rio Turvo Sujo

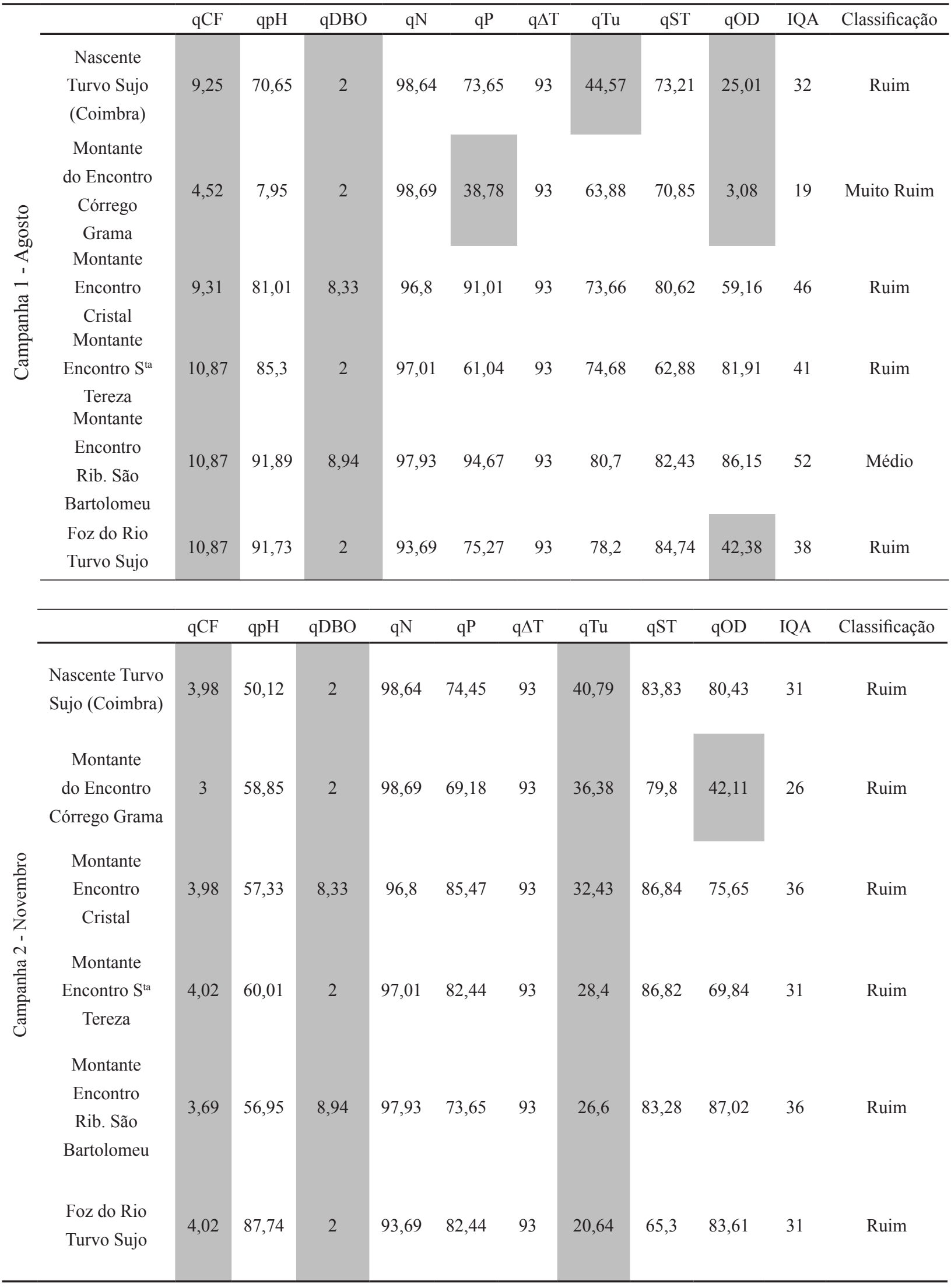

\section{REVENG}

459-468 p. ENGENHARIA NA AGRICUltura, ViÇOSA - MG, V.19 N.5, SETEMBro / OUTUBRO 2011 
Quadro 5. Continuação

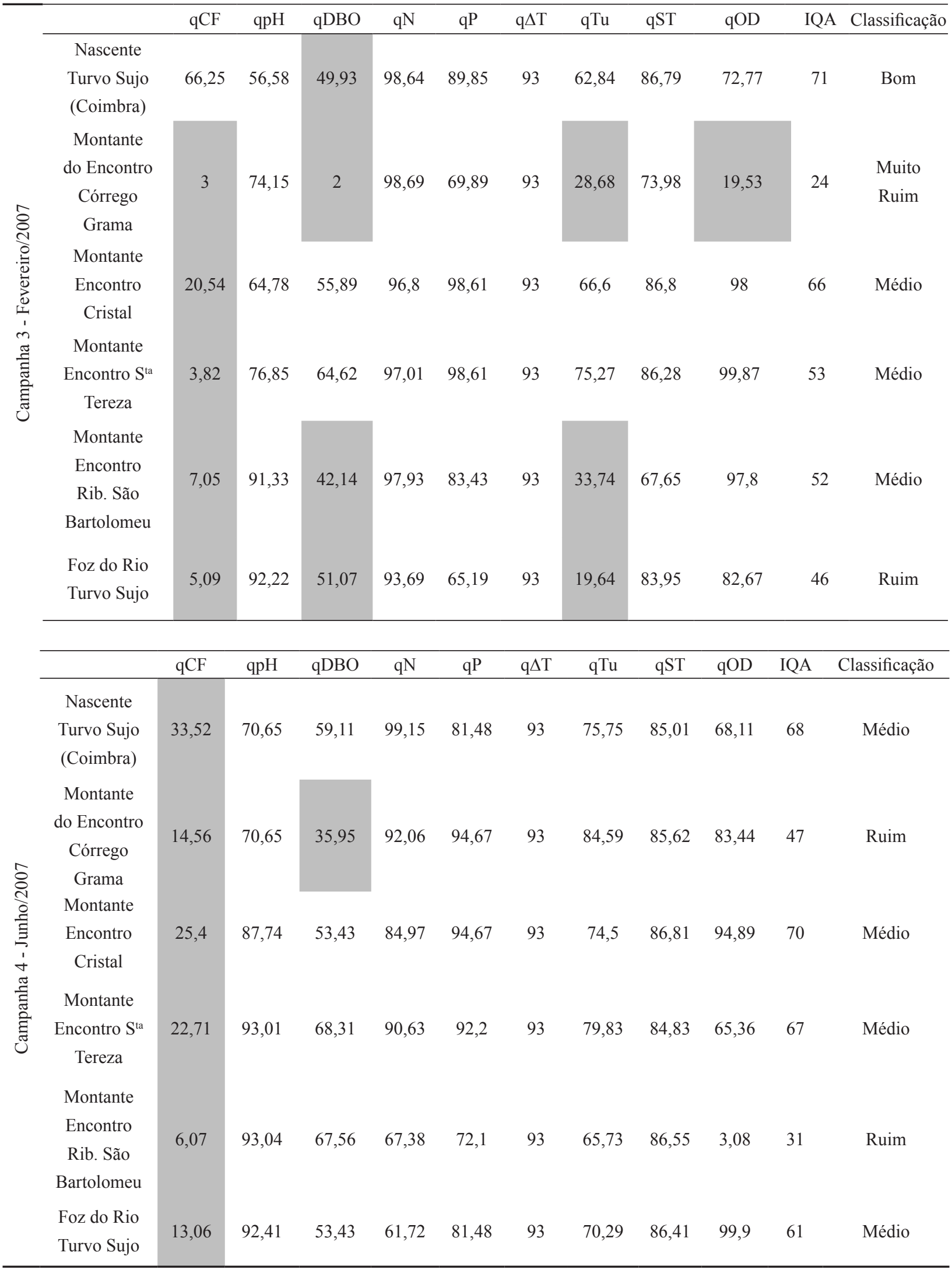


Outra variável que influenciou muito negativamente no IQA foi a DBO $\left(\mathrm{q}_{\mathrm{DBO}}\right)$, indicando $o$ lançamento de grandes concentrações de cargas orgânicas, devido novamente aos despejos oriundos das cidades do entorno da bacia. Estes efluentes urbanos são lançados sem qualquer tipo de tratamento, provocando queda da qualidade da água.

A turbidez $\left(\mathrm{q}_{\mathrm{Tu}}\right)$ também influenciou a queda do IQA, principalmente na campanha 2 , realizada no mês de novembro, quando ocorre o início das chuvas, acarretando maior aporte de sedimentos nos cursos de água pelo aumento do escoamento superficial.

A variável OD $\left(\mathrm{q}_{\mathrm{OD}}\right)$ também interferiu no IQA negativamente, levando-o a uma classificação "MUITO RUIM" no ponto a montante do córrego do Grama, situado a jusante da cidade de Coimbra, onde o Rio Turvo Sujo recebe grande carga de efluentes urbanos, e estando ainda próximo de sua nascente, não tem vazão suficiente para amortecer o impacto dos despejos, ou seja, sua capacidade de autodepuração é ineficiente.

\section{CONCLUSÕES}

- Houve expressiva melhoria da qualidade da água nos períodos com maior vazão, notadamente no trecho correspondente à nascente do Rio Turvo Sujo. Durante o período de estiagem, a classificação da qualidade da água manteve-se entre "muito ruim" e "médio", sendo o ponto de pior qualidade a montante da confluência do Rio Turvo Sujo com o córrego do Grama;

- A qualidade das águas do Rio Turvo Sujo foi classificada, em geral, de média a ruim; e

- As variáveis que mais interferiram negativamente no IQA foram: coliformes termotolerantes $(\mathrm{CF})$, demanda bioquímica de oxigênio (DBO), turbidez ( $\mathrm{Tu}$ ) e oxigênio dissolvido (OD).

\section{REFERÊNCIAS BIBLIOGRÁFICAS}

ALMEIDA, T.V. de. Índice de qualidade da água e coeficientes de autodepuração de trechos do Rio Pomba. Viçosa: UFV, 2006. 68f. (Dissertação de Mestrado).

APHA - American Public Health Association. Standard methods for the examination of water and wastewater. $20^{\mathrm{a}}$ ed. Washington: APHA, 1998.

CETESB - Companhia de Tecnologia de Saneamento Ambiental http://www.cetesb.sp.gov.br/Agua/rios/ indice.asp. 12 ago. 2007.

COMBASB - Conselho Municipal de Desenvolvimento da Bacia do São Bartolomeu - Projeto: Gerenciamento integrado da bacia hidrográfica do Ribeirão São Bartolomeu em Viçosa, MG. (Relatório Interno). 1994. 21p.

IBGE - Instituto Brasileiro de Geografia e Estatística. Brasil http://www.ibge.gov.br/home/estatistica/ populacao/contagem 2007/contagem_final/ tabela1_1_17.pdf. 3 abr. 2008.

IGAM - Instituto Mineiro de Gestão das Águas. Relatório de monitoramento das águas superficiais na Bacia do Rio Docel em 2005. Belo Horizonte: Projeto Águas de Minas, 2006.

IGAM - Instituto Mineiro de Gestão das Águas. Relatório de monitoramento das águas superficiais na Bacia do Rio Paraíba do Sul em 2003. Belo Horizonte: Projeto Águas de Minas, 2004.

MATOS, A.T. Qualidade do solo e da água. Série Caderno Didático n. 33. Viçosa: DEA-UFV, 2004.

ONGLEY, E.D. Controle da poluição da água pelas atividades agrícolas; tradução de H.R. GHEYI, F.A.V. DAMASCENO, L.T. de L. BRITO. Campina Grande: UFPB. 2000.

RIBEIRO, P. R. S. Caracterização química, física e microbiológica de cursos d'água da bacia do Rio Turvo Limpo. Viçosa: UFV, 2002. 153p. (Dissertação de Mestrado). 